\title{
AGGRESSIVE DRIVING: ASSOCIATIONS BETWEEN CAR'S BRAND AND DRIVER'S GENDER AMONG YOUNG DRIVERS IN LATVIA
}

\section{SUMMARY}

Introduction. In Latvian community, there is a strong social belief that BMW owners are more aggressive than the drivers of other car brands.

Aim of the Study. To investigate the effects of private car's brand (BMW vs. non-BMW), driver's gender, and their interaction on self-reported aggressive driving behaviour among young Latvian drivers.

Materials and Methods. Forty BMW owners and forty other brand owners (20 males and 20 females in each group) aged between 20 and 30 years, filled out the 'Aggressive Driving Scale' (ADS, Valtere, Perepjolkina, 2006).

Results. It was established that drivers owning a sedan type BMW cars reported more aggressive driving behaviour than the drivers of other sedan type vehicle brands, irrespective of their gender.

Conclusions. This implies that the vehicle itself, its image or other drivers' assumptions about it may possibly influence the behaviour of the driver.

Key words: aggressive driving, young drivers, brand of the car, BMW, gender

\section{INTRODUCTION}

Recent increases in the numbers of purchased vehicles and novice young drivers in Latvia, on the one hand, and the high rate of traffic accidents and fatal crashes, on the other hand, as well as still relatively low traffic culture in Latvia mean that it is important to understand the factors contributing to risky and aggressive driver behaviour that may potentially lead to a traffic accident.

It is evident from the researches that it is necessary to consider driver characteristics, vehicle characteristics, and the driver-vehicle interaction in order to better understand the factors that contribute to the risky driving and crashes. There is a common understanding among researchers that individual differences play a role in the driving performance. Previous studies have shown that mostly young, male and inexperienced drivers commit aggressive driving behaviours rather than young female drivers and aged drivers (Deffenbacher et.al., 2000; Shinar, 1998; Doherty et. al., 1998; Blockey, Hartley, 1995; Evans, 1991), as well as drivers endorsing a macho personality image (Özkan, 2006), and drivers owning high-performance cars (Krahe, Fenske, 2002). Young drivers are also more likely to get annoyed by other drivers and react in a more violent manner than aged drivers (Lajunen, Parker, 2001). The other essential intrinsic factors associated with driver behaviours, performance and accident liability are gender roles (cited in Özkan, 2006), risk perception and personality (Elander et. al., 1993, Miles, Johnson, 2003). There is some evidence that personal and vehicle characteristics can influence driver behaviour independently. In an exploration of the impact of various driver characteristics on driver behaviour, B. Krahe 
and I. Fenske (Krahe, Fenske, 2002) explored the role of personality, age and power of car as predictors of aggressive driving behaviour.

Little research has investigated the social and personal perceptions that may affect drivervehicle interactions. For example, in reference to drivers owning high-performance cars it was shown, that simply owning the high-performance vehicle was associated with aggressive driving, irrespective of personality or age (Krahe, Fenske, 2002). This implies that the vehicle itself influenced the behaviour of the driver (Smyth, King, 2006). With respect to the driver-vehicle interaction it is important to know the extent to which this is determined by the performance characteristics of the vehicle and the extent to which it is determined by the driver's pursuit of different behaviours in a different vehicle, because of its image or other assumptions about it (Smyth, King, 2006). An important question to be considered is when a car that is perceived by the driver to have a particular image is being driven, does the driver behave in a way which they see as being consistent with the image?

In Latvian community, there is a strong social belief that BMW owners are more aggressive than drivers of other car brands. Even Latvian insurance companies count BMWs as a risk group, and that is why BMW-owners have to pay more for their car insurance. It is necessary to mention that in Latvia BMW cars are very popular among young people especially among young-maledrivers.

\section{AIM OF THE STUDY}

The purpose of the present study was to find out the links between aggressive driving, car's brands (BMW and non-BMW) and gender among young drivers in Latvia.

\section{Hypotheses}

We predicted that: (1) Irrespective of the driver's gender, sedan type BMW drivers would report more aggressive driving behaviour than non-BMW sedan type vehicle drivers. (2) Aggressive driving behaviour would be shown more frequently by male drivers in comparison with female drivers irrespective of the vehicle's brand. (3) There will be no interaction between the drivers' gender and vehicle's brand in self-reported aggressive driving behaviour among young drivers in Latvia.

\section{MATERIALS AND METHODS}

\section{Participants}

The sample consisted of eighty young (40 male and 40 female) drivers from Riga, Latvia, aged between 20 and 30 years $(\mathrm{M}=24.23 ; \mathrm{SD}=3.30$ - mean 24.50 years for male drivers and 23.95 years for female drivers). All participants had a driving license and driving experience from 1 to 11 years (mean driving age 4.2 years -4.6 years for male drivers and 3.8 years for female drivers). In each group 50\% of participants were BMW-owners and 50\% - non-BMW-owners. Mean driving age in the BMW-owner's sample was 4.0 years and in the non-BMW-owners sample -4.4 years, meanwhile mean age in BMW-owners sample was 25.55 years, but in non-BMW-owners sample - 23.90 years. All participants had sedan-type cars with 2 litre engine.

\section{Instruments}

The participants filled out a newly developed "Aggressive Driving Scale" (ADS, Valtere, Perepjolkina, 2006) and answered on questions related to their demographic and background variables such as age and sex. In addition, participants were asked to indicate their driving age (how long they have held a driving license and how regularly they drive a car), as well as the car's brand that they are driving and the power of engine (in litres). 
"Aggressive Driving Scale" (ADS, Valtere, Perepjolkina, 2006) was developed as a behavioural self-reported scale which consists of 17 items that cover different types of aggressive and hostile behaviour when driving. The questions were designed to assess both ordinary and aggressive violations as well as hostile aggressive behaviours and aggressive warnings one can commit while driving. Participants were asked to indicate how often they committed each of the behaviours using a 3 -point scale $(0=$ almost never, $1=$ sometimes, $2=$ often $)$. Sample item for aggressive traffic violations include "How often do you exceed the speed limit?", sample item for hostile behaviour: "Do you try to block the road for vehicles wishing to pass your car in an insolent manner?". Higher scores on ADS scale reflect higher levels of aggressive driving. Additionally to ADS total score two subscales can be formed: (1) 'Ordinary and aggressive driving violations' (11 items: 1-6, 10-14)) and (2) 'Drivers' hostile behaviour and aggressive warnings' (6 items: 7-9, 15-17).

It should be noted that the main aim in developing a new aggressive driving scale was to obtain a reliable behavioural scale in the Latvian language for measuring self-reported aggressive driving behaviours in traffic with "nation specific aggressive driving items" (cited in Özkan, 2006) to capture local aspects of aggression in traffic and in compliance with Article 122.3 on "Aggressive Driving" in Code of Administrative Offences of the Republic of Latvia*.

The results of the present study indicated that the ADS total scale and both subscales have acceptable internal consistency. Reliability coefficients were satisfactory as for the total ADS score (Cronbach's alpha $=.86$ ) as well as for both subscales (Cronbach's alpha $=.82$ and .72 , respectively).

\section{Procedure}

The survey was conducted in Riga, Latvia, in the period of September-October, 2008. Potential participants were electronically mailed a link to a questionnaire and a covering letter with an invitation to participate in the survey if they are 20-30 years old, have a driving license and at least 1 year of active driving experience. Additionally they were asked to forward the invitation letter with the link to other acquaintances who would match the mentioned criteria, especially if the person drives a BMW. The participants were assured of anonymity and confidentiality. 136 participants completed and returned a questionnaire via internet. To provide even samples, 20 questionnaires were randomly selected from every respondent subgroup to be likened to the smallest subgroup of BMW female drivers. Consequently, a total of 80 participants were included in the analyses.

The data were analysed by using descriptive statistics, reliability analysis (Cronbach's Alpha), Independent-Samples t-test, and Univariate Analyses of Variance (UNIANOVA).

\section{RESULTS}

The sum score of ADS and sum scores of the two subscales were used in the analyses.

Univariate Analyses of Variance were conducted to the test for the effects of car's brand (hypothesis 1) and gender (hypothesis 2) on ADS scores as well as to the test of the third hypothesis.

Our findings show that only two hypothesis (hypothesis 1 and 3) were confirmed. Univariate Analyses of Variance revealed, that there exists a vehicle's brand effect on the selfreported aggressive driving behaviour: ADS total score $\left(\mathrm{F}=7.09, \mathrm{p}<.01, \eta^{2}=.085\right)$, 'Ordinary

* Latvijas Aministratīvo pārkāpumu kodeksa 122.3 pants "Par agresīvu braukšanu". 
and aggressive driving violations' $\left(\mathrm{F}=4.97, \mathrm{p}<.05, \eta^{2}=.061\right)$ and 'Drivers' hostile behaviour and aggressive warnings' $\left(F=7.14, p<.01, \eta^{2}=.086\right)$ (see Pictures $\left.1-3\right)$. In all three cases the vehicle's brand effect is of a middle size.

Results of Univariate Analyses of Variance clearly showed that there is no gender effect on the self-reported aggressive driving behaviour: $\operatorname{ADS}$ total score $\left(F=.35, p>.1, \eta^{2}=.005\right)$, 'Ordinary and aggressive driving violations' $\left(\mathrm{F}=.45, \mathrm{p}>.1, \eta^{2}=.006\right)$ and 'Drivers' hostile behaviour and aggressive warnings' $\left(\mathrm{F}=.88, \mathrm{p}>.1, \eta^{2}=.001\right)$ (see Pictures $\left.1-3\right)$, as well as the effect of driver's gender and vehicle's brand interaction on the self-reported aggressive driving behaviour is not considerable: ADS total score $\left(\mathrm{F}=1.19, \mathrm{p}>.1, \eta^{2}=.015\right)$, 'Ordinary and aggressive driving violations' $\left(\mathrm{F}=2.26, \mathrm{p}>.1, \eta^{2}=.029\right)$ and 'Drivers' hostile behaviour and aggressive warnings' $(\mathrm{F}=$ $\left..16, \mathrm{p}>.1, \eta^{2}=.000\right)($ see Pictures $1-3)$.

It was interesting to test whether male drivers really scored similarly to female drivers on every ADS item within BMW-drivers and non-BMW-drivers subsamples. Independent-Samples ttest analysis showed that statistically significant difference between male and female drivers' responses on ADS items within 'non-BMWdrivers' sample was established only in the first item: "(1) How often do you overtake several vehicles in a traffic jam using an opposite lane?" $(\mathrm{t}=2.6, \mathrm{p}<.05)$ - surprisingly female drivers scored higher on this item. No differences in ADS total score and subscale scores between male and female drivers within 'non-BMWdrivers' subsample were found.

Independent-Samples t-test analysis showed that statistically significant difference between male and female drivers' responses on ADS items in 'BMW-drivers' subsample was established only on three ADS items: “(2) How often when in a traffic jam you switch lanes several times in order to pass a vehicle?" $(\mathrm{t}=3.18, \mathrm{p}<.01)$, " (12) How often do you exceed the speed limit when you are in a hurry?" $(\mathrm{t}=2.76, \mathrm{p}<.01)$ and “(15) Do you get angry with the pedestrians slowly crossing pedestrian crossings?" $(\mathrm{t}=2.40, \mathrm{p}<.05)$ - male drivers scored higher on these items. No differences in ADS total score and subscales scores between male and female drivers within 'BMW-drivers' subsample were found.

Independent-Samples t-test analysis showed that statistically significant difference between 'non-BMW-drivers' and 'BMWdrivers' drivers responses on ADS items within

Picture 1. Mean Aggressive Driving Scale's scores in non-BMW-drivers and $B M W$-drivers samples across males and females

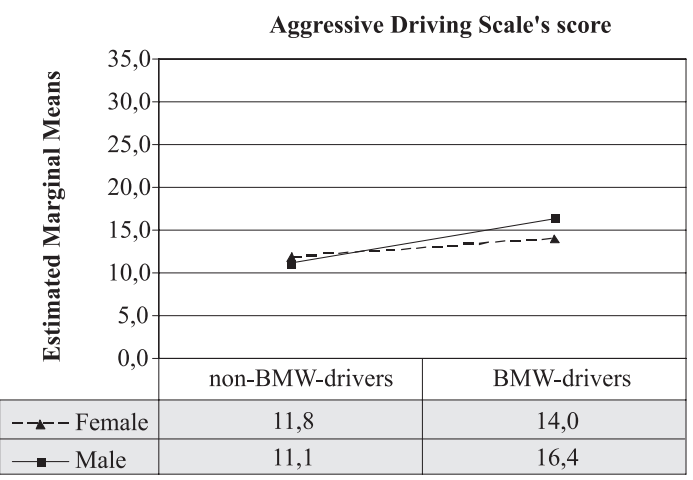

Picture 2. Mean 'Ordinary and aggressive driving violations'subscale's scores in non$B M W$-drivers and $B M W$-drivers samples across males and females

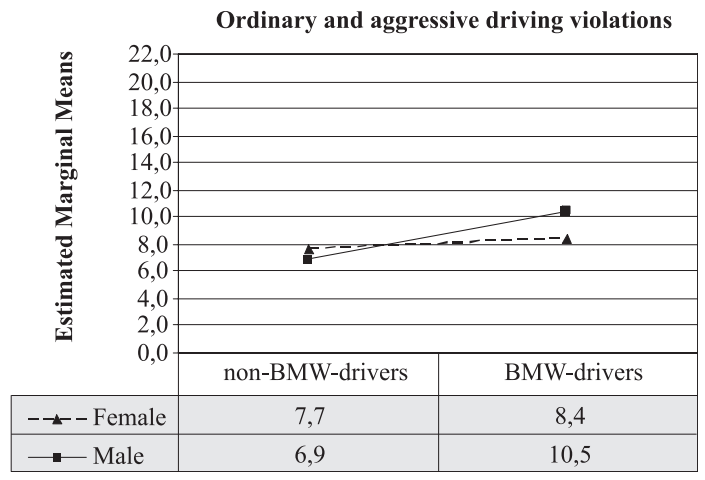


female subsample was established only in one item: "(7) How often do you use the horn in populated areas when you are dissatisfied with something taking place on the road?" $(\mathrm{t}=3.24$, $\mathrm{p}<.01$ ) - BMW female drivers scored higher on this item. No differences were found on ADS total score and subscale scores. No differences in ADS total score and subscale scores between 'non-BMW-drivers' and 'BMW-drivers' within female subsample were found.

Independent-Samples t-test analysis showed that statistically significant difference between 'non-BMW-drivers' and 'BMWdrivers' drivers responses on ADS items within male sample were found on 6 items: "(1) How
Picture 3. Mean 'Drivers' hostile behaviour and aggressive warnings' subscale's scores in non-BMW-drivers and $B M W$-drivers samples across males and females

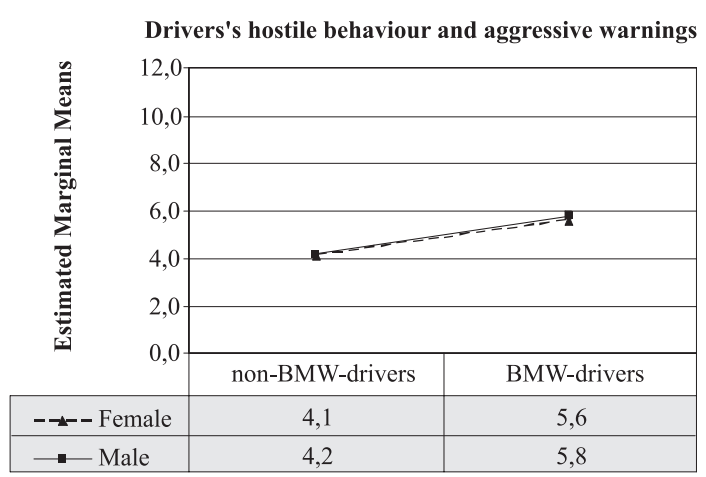

often do you overtake several vehicles in a traffic jam using an opposite lane?" $(t=1.99, \mathrm{p}<.05)$, "(2) How often you switch lanes several times in order to pass a vehicle when you are in a traffic jam?" (t=3.32, $\mathrm{p}<.01)$, “(5) How often do you overtake a car using a lane dedicated for public transport?" ( $\mathrm{t}=2.28, \mathrm{p}<.05)$, “(11) How often do you exceed the speed limit?" $(\mathrm{t}=2.30, \mathrm{p}<.05)$, "(12) How often do you exceed the speed limit when you are in a hurry?" $(\mathrm{t}=2.60, \mathrm{p}<.05)$ and "(16) Do you try to block the road for vehicles wishing to pass your car in an insolent manner?" $(\mathrm{t}=2.20, \mathrm{p}<.05)$, as well as for ADS total score $(\mathrm{t}=2.40, \mathrm{p}<.05)$, 'Ordinary and aggressive driving violations' $(\mathrm{t}=2.40, \mathrm{p}<.05)$ and 'Drivers' hostile behaviour and aggressive warnings' $(\mathrm{t}=1.96, \mathrm{p}<$ $.05)$ - BMW-male-sex-drivers scored higher on all items mentioned above and on all ADS scales as well.

\section{Discussion}

In the present study it was analyzed whether private car's brand and driver's gender are associated with aggressive driving. It was found that drivers owning sedan type BMW cars reported more aggressive driving behaviour than the drivers of other sedan type vehicle brands irrespective of their gender.

Results show that the driver's behaviours in traffic may be influenced not only by the performance characteristics of the vehicle, but also by the vehicle's image or other drivers' assumptions about it. Results of the present study do not explain why BMW-drivers reported more aggressive behaviour than non-BMW-drivers.

One of the possible explanations of the current research results may be that when a car that is perceived by the driver to have a particular image is being driven, drivers behave in a way which they see as being consistent with the image of the car. In Latvian community BMW-drivers are strongly associated with aggressive driving style and so, might be drivers act or at least report in compliance with this social believe. This social believe might be used by BMW-drivers as some kind of allowance to act in an aberrant way. It would be interesting to find out whether people drive BMWs differently because they view their own presence on the road as a BMW-with-a-driver as qualitatively different to their presence as a non-BMW-with-a-driver, and therefore behave differently in their interactions with other road users.

Another explanation may be that people with particular personality characteristics (e. g. 
aggressiveness, impulsivity, high-temper, recklessness, sensation seeking etc.) which are associated with risky and aggressive driving give a preference to a particular type and even may be brand of the car.

Another possibility is that drivers buy BMW-brand vehicles endorsing the macho personality image. It is possible that 'macho-persons' not only act more aggressively on the road (Krahe, Fenske, 2002), but also they give preference to high-performance and sport-type cars and are more sensitive to image related issues.

According to M. Sheller (Sheller, 2004) a disregarded aspect of car cultures is the emotional investments people have in the relationships between the car, themselves and others. These emotional investments create affective contexts that are manifest for example in particular types of vehicles. So car manufactures frequently manipulate brand desire through emotional meaning in their advertising campaigns, and the feelings generated can be strong indicators of emotions embedded within car cultures (Sheller, 2004, cited in Smyth, King, 2006). This is perhaps demonstrated by the sexualisation of the vehicle by the media. Inherent in this view is the car as an extension of the driver's body, as found in advertising and pop culture, such as song lyrics, music videos and motor shows (Sheller, 2004, cited in Smyth, King, 2006). In such contexts, the vehicle is seen to possess a personality and contributes to the ego-formation of the driver as competent, powerful and sexually desirable. Car consumption then is not a rational choice but rather it reflects a result of the interaction between aesthetic, emotional and sensory responses to driving, as well as daily living, work and social patterns (Smyth, King, 2006).

How people perceive themselves and their cars can be explained by social cognition theory. Much of the research in social cognition has been concerned with individual conceptions of the self, that is, the person's mental representations of their own personality attributes, social roles, etc. (Fiske, Taylor, 2000). Self-categorisation theory considers that self-perception is highly contextdependent (Onorato, Turner, 2004). While aspects of the self-concept may be relatively stable, it has also been demonstrated that situational contexts can lead people to think about themselves in ways that are at variance with their stable self-concept (Onorato, Turner, 2004). Also, stable self-conceptions may contain inconsistent elements, as people may have multiple self-conceptions with varied features and a particular self-concept may be activated at a particular time due to situational factors that may be at variance with other stable aspects of the self-concept (Fiske, Taylor, 2000; Onorato, Turner, 2004). Driving a vehicle, even a specific vehicle such as one's own car, could be one of these contexts which elicits a context-specific self-concept, presumably with its own particular influence on behaviour. It would therefore be possible for people who regard themselves as generally passive and law-abiding to become aggressive and non-compliant in the driving situation, and even have different self-concepts activated by driving different types of vehicles (Smyth, King, 2006).

Work on the emotional aspects of vehicles provides more promise, especially if the reflexive link is made between the image of a particular vehicle as the object of desire and purchase, and the self-image of the purchaser/driver and the consequent production of behaviour (Smyth, King, 2006). Social cognition theories which allow for context-specific self-schemas provide a betterdeveloped theoretical basis for this approach.

Future studies should examine mentioned possibilities considering the limitations of this study.

It is necessary to mention, that there are limitations associated with the use of self-reported 
measure, such as an over-reliance on self-report data, as been remarked by E. R. Dahlen et. al. (Dahlen et. al., 2005). It has been identified that there is a tendency for participants to engage in "impression management" and self-deception when completing traffic behaviour inventories, which may lead to the under-reporting of dangerous, illegal or socially inappropriate driving behaviour (cited in Lajunen et. al., 1997). On the other hand as the respondents completed the ADS questionnaire anonymously and couldn't gain anything by giving embellished responses, it may be expected, that the bias caused by socially desirable responding is very small (cited in Lajunen, Summala, 2003), but it is still likely that there is a difference between self-reported and actual behaviour in traffic even though several studies have indicated that self-reports of driving correspond well to actual driving behaviour (cited in Ingham, 1991; West et. al., 1993).

\section{CONCLUSIONS}

As it was predicted, drivers owning sedan type BMW cars reported more aggressive driving behaviour than the drivers of other sedan type vehicle brands, irrespective of their gender. This implies that the vehicle itself may possibly influence the behaviour of the driver. Contrary to the expectations and many other research findings there was no impact of the drivers' gender registered in self-reported aggressive driving behaviour. Impact of the drivers' gender appeared slightly only within the BMW-driver's sample - BMW-male-drivers scored statistically higher in three ADS items related to frequent line switching, speeding and irritation in comparison with BMW-female-drivers. As it was expected no considerable interaction between drivers' gender and vehicle's brand in self-reported aggressive driving behaviour was found among young drivers in Latvia.

\section{REFERENCES}

1. Blockey, P. N., Hartley, L. R. (1995) Aberrant Driving Behaviour: Errors and Violations. Ergonomics, 38(9), London: Taylor \& Francis Group, p. 1759-1771.

2. Dahlen, E. R., Martin, R. C., Ragan, K., Kuhlman, M. M. (2005) Driver Anger, Sensation Seeking, Impulsiveness, and Boredom Proneness in the Prediction of Unsafe Driving. Accident Analysis and Prevention, 37 (2). Oxford: Elsevier, p. 341-348.

3. Deffenbacher, J. L., Huff, M. E., Lynch, R., Oetting, E. R., Salvatore, N. F. (2000) Characteristics and Treatment of High-Anger Drivers. Journal of Counselling Psychology, 47, Washington: APA Journals, p. 5-17.

4. Doherty, S. T., Andrey, J. C., MacGregor, C. (1998) The Situational Risks of Young Drivers: The Influence of Passengers, Time of Day and Day of Week on Accident Rates. Accident Analysis and Prevention, 30 (1), Oxford: Elsevier, p. 45-52.

5. Elander, J., West, R., French, D. (1993) Behavioral Correlates of Individual Diferences in Road Traffic Crash Risk: an Examination of Methods and Findings. Psychological Bulletin, 113(2), Washington: American Psychological Association, p. 279-294.

6. Evans, L. (1991) Traffic Safety and the Driver. New York: Van Nostrand Reinhold, 404 p.

7. Fiske, S. T., Taylor, S. E. (1991) Social Cognition. New York: McGraw-Hill, 560 p.

8. Ingham, R. (1991) The Young Driver. Paper presented to the Conference New Insights into Driver Behaviour, organized by PACTS (Parliamentary Advisory Council for Transport Safety), London, 21 October 1991. 
9. Krahe, B., Fenske, I. (2002) Predicting Aggressive Driving Behavior: The Role of Macho Personality, Age, and Power of Car. Aggressive Behavior, 28 (1), New York: Wiley-Liss, Inc, p. 21-29.

10. Lajunen, T., Corry, A., Summala, H., Hartley, L. (1997) Impression Management and Self-Deception in Traffic Behaviour Inventories. Personality and Individual Differences, 22(3), Oxford: Elsevier, p. 341353.

11. Lajunen, T., Parker, D. (2001) Are Aggressive People Aggressive Drivers? A Study of the Relationship between Self-Reported General Aggressiveness, Driver Anger and Aggressive Driving. Accident Analysis and Prevention, 33 (2), Oxford: Elsevier, p. 243-255. www.elsevier.com/locate/aap (26.06.2009.).

12. Lajunen, T., Summala, H. (2003) Can we Trust Self-Reports of Driving? Effects of Impression Management on Driver Behaviour Questionnaire Responses. Transportation Research Part F, 6, Oxford: Elsevier, p. 97-107.

13. Miles, D. E., Johnson, G. L. (2003) Aggressive Driving Behaviors: Are there Psychological and Attitudinal Predictors? Transportation Research, Part F, 6, Oxford: Elsevier, p. 147-161.

14. Onorato, R. S., Turner, J. C. (2004) Fluidity in the Self-concept: The Shift from Personal to Social Identity. European Journal of Social Psychology, 34 (3), Chichester: Wiley, p. 257-278.

15. Özkan, T. (2006) The Regional Differences between Countries in Traffic Safety: A Cross-Cultural Study and Turkish Case. Academic Dissertation. Research Reports, No 37. University of Helsinki, p. 63.

16. Sheller, M. (2004) Automotive Emotions: Feeling the Car. Theory, Culture and Society, 21(4/5), London: Sage, p. 221-242.

17. Shinar, D. (1998) Aggressive Driving: The Contribution of the Driver and the Situation. Transportation Research Part F, 1(2), Oxford: Elsevier, p. 137-160.

18. Smyth, T. L., King, M. J. (2006) Driver-Vehicle Interactions in 4WDs: A Theoretical Review. In: Australasian Road Safety Research, Policing Education Conference, 25-27 October 2006, Gold Coast, Queensland, Australia. http://eprints.qut.edu.au/6241/1/6241_1.pdf (02.07.2009.).

19. Valtere, S., Perepjolkina, V.(2006) Agresīvās braukšanas skala [Aggressive Driving Scale]. Unpublished material (In Latvian).

20. West, R., French, D., Kemp, R., Elander, J. (1993) Direct Observation of Driving, Selfreports of Driver Behaviour and Accident Involvement. Ergonomics, 36, UK: Taylor \& Francis Group, p. 557-567.

Lector, researcher Mg. psych. Viktorija Perepjolkina

Riga Teacher Training and Educational Management Academy

Psychological Research Institute of the Faculty of Psychology

Address: Sesku iela 7/2, 61, Rīga, LV-1035

Phone: +371 67572946

E-mail: viktorija@rpiva.lv

Acknowledgements

Thanks to Evita Armalovicha for her contribution to the data collection. 